\title{
Certolizumab pegol, a monthly subcutaneously administered Fc-free anti-TNF $\alpha$, improves health-related quality of life in patients with moderate to severe Crohn's disease
}

\author{
Paul Rutgeerts • Stefan Schreiber • Brian Feagan • \\ Dorothy L. Keininger • Liz O'Neil • \\ Richard N. Fedorak • \\ CDP870 Crohn's Disease Study Group
}

Accepted: 17 October 2007 / Published online: 11 December 2007

(C) Springer-Verlag 2007

\begin{abstract}
Background and aims Certolizumab pegol, a polyethylene
Abstract
Background and aims Certolizumab pegol, a polyethylene glycolated Fc-free Fab' was efficacious and well tolerated in patients with moderate-to-severe Crohn's disease in a previously reported randomized, placebo-controlled study.
\end{abstract}

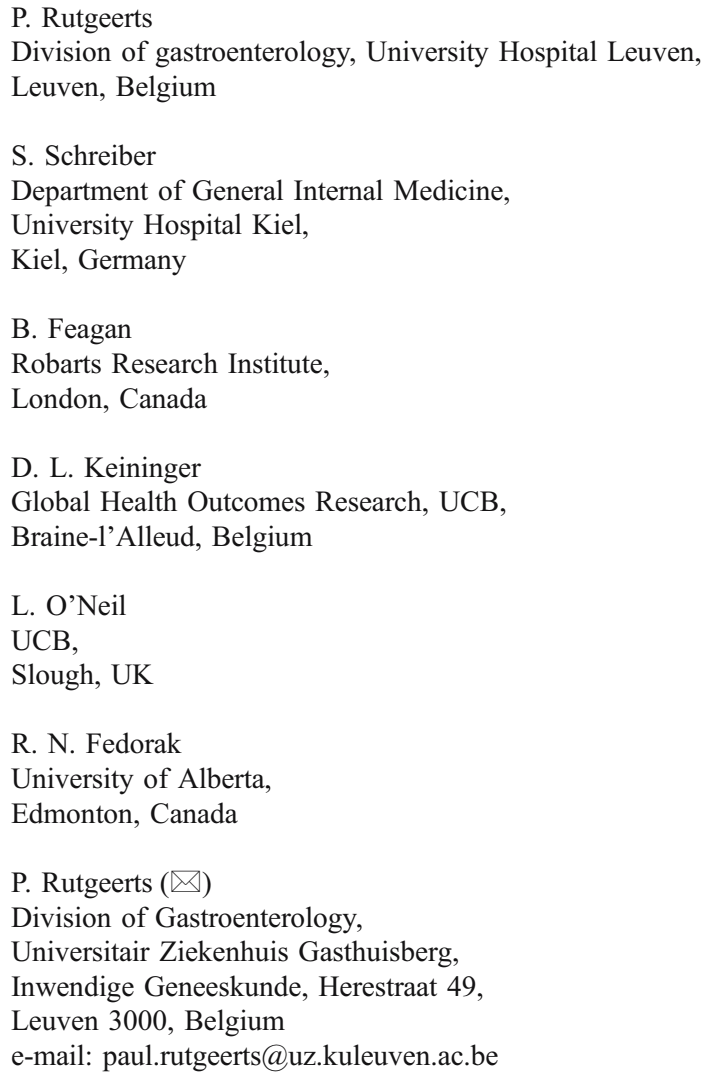
In this paper, we report the effect of certolizumab pegol on health-related quality of life (HRQoL).

Materials and methods Patients with moderate-to-severe active Crohn's disease $(n=292)$ received subcutaneous certolizumab pegol 100,200 , or $400 \mathrm{mg}$ or placebo at weeks 0,4 , and 8 . A post hoc analysis of the intent-to-treat population (290 patients with HRQoL data) assessed HRQoL by evaluating patients' responses to the selfadministered inflammatory bowel disease questionnaire (IBDQ) at baseline and weeks 2, 4, 6, 8, 10, and 12.

Results Patients receiving certolizumab pegol $400 \mathrm{mg}$ at weeks 0,4 , and 8 demonstrated, via their IBDQ total score, significantly $(P \leq 0.05)$ greater improvement in HRQoL from baseline to week 12 and at all other time points compared with placebo. Moreover, HRQoL improved over time in all certolizumab pegol groups, irrespective of baseline Creactive protein levels. Emotional well-being (IBDQ Emotional Function domain) improved throughout the study for patients receiving certolizumab pegol $400 \mathrm{mg}$. This improvement was significantly $(P \leq 0.05)$ greater than for patients receiving placebo at all time points. In addition, systemic symptoms (IBDQ Systemic Symptoms domain) improved significantly more in patients receiving certolizumab pegol $400 \mathrm{mg}$ than in those receiving placebo at weeks 4 , 8,10 , and $12(P \leq 0.05)$ and approached statistical significance at week $2(P=0.054)$.

Conclusion This analysis suggests that certolizumab pegol $400 \mathrm{mg}$ improves HRQoL in patients with moderateto-severe Crohn's disease.

Keywords Crohn's disease - Immunotherapy · Quality of life $\cdot$ Inflammatory bowel disease 


\section{Introduction}

Crohn's disease is a chronic relapsing and remitting, inflammatory bowel disease (IBD) that has a significant impact on health-related quality of life (HRQoL) [1, 2]. HRQoL has been recognized as an important health outcome and has been defined in the medical setting as "a concept encompassing a broad range of physical and psychological characteristics and limitations which describe an individual's ability to function and derive satisfaction from doing so" [3]. Crohn's disease frequently begins in early adulthood, causing a heavy disease burden in a relatively young patient population. Consequently, many patients will be affected for most of their adult life.

In Crohn's disease, health status is affected as much by psychosocial factors and functional status as by disease activity [4]. For example, the need to wear an ostomy bag may adversely affect self-image, and this has been reported to be a common worry for patients with Crohn's disease [5]. Moreover, previous studies have demonstrated a high correlation between disease severity, as measured by the Crohn's Disease Activity Index (CDAI) [6], and HRQoL, as assessed using the Inflammatory Bowel Disease Questionnaire (IBDQ) [7, 8]. A large longitudinal study prospectively assessed the HRQoL of patients with Crohn's disease over 1 year and determined influencing factors [9]. The following factors were associated with a negative impact on overall HRQoL: female gender, tobacco use, active Crohn's disease, involvement of the colon, hospitalization, corticosteroid treatment, and surgery in the past 3 months (order does not indicate priority). These findings were reflected in a survey of patients with a long-term diagnosis of Crohn's disease [10]. It is therefore important to include improvement in HRQoL as a key therapeutic goal in the treatment of patients with Crohn's disease.

Conventional treatment options for Crohn's disease include aminosalicylates, antibiotics, corticosteroids, immunomodulators, and surgery. However, in some patients, the disease can be refractory or unresponsive to certain pharmacologic treatments. Furthermore, corticosteroids are associated with a risk of dependency and potentially serious side effects (e.g., diabetes, osteoporosis, moon face, and acne), which are detrimental to a patient's HRQoL and may negatively affect self-esteem [11-13]. Such treatments therefore require careful management. Additionally, it is rarely possible to achieve long-term relief from Crohn's disease with a single surgical procedure, and as a result, patients with Crohn's disease fear surgery so much that their HRQoL is reduced [14].

It is now well accepted that tumor necrosis factor $\alpha$ $(\mathrm{TNF} \alpha)$ plays a pivotal role in the underlying inflammatory pathophysiology of Crohn's disease [15]. Furthermore, neutralization of $\mathrm{TNF} \alpha$ has been shown to improve the symptoms of this debilitating illness $[13,16]$. Infliximab has been shown to improve HRQoL, as measured by the IBDQ and the Short-Form Health Survey (SF-36) [8, 17], but the occurrence of infusion reactions along with the risk of developing anti-infliximab antibodies, which can reduce long-term efficacy [18], could negatively impact HRQoL over time. Patients may feel that subcutaneous treatment has advantages over treatments requiring infusion; a long stay at the clinic may negatively impact a patient's daily life. This increased freedom in patient treatment management may lead to improved treatment compliance with a consequent impact on therapeutic outcomes. Thus, there is a need for alternative long-term therapies for moderate-tosevere Crohn's disease that have minimal negative impact on patients' everyday life while also reducing the impact of the disease on patients' HRQoL [19].

Certolizumab pegol is the first polyethylene glycolated (PEGylated) anti-TNF $\alpha$ antibody fragment (Fab') to be studied in Crohn's disease. Unlike conventional anti-TNF agents, certolizumab pegol lacks the crystallizable fragment (Fc) region, thus potentially avoiding unwanted effects [20]. PEGylation increases the plasma half-life and reduces the frequency of dosing required. Certolizumab pegol is administered by subcutaneous injection once every 4 weeks (more frequent dosing may be used during an induction phase). Certolizumab pegol $400 \mathrm{mg}$ administered subcutaneously demonstrated efficacy and was well tolerated in patients with moderate-to-severe active Crohn's disease in phases II [21] and III (PRECiSE 1 and PRECiSE 2 [22, 23]) studies. Certolizumab pegol has also demonstrated clinical efficacy and good tolerability in patients with rheumatoid arthritis [24, 25].

This is the first paper to report the effect of certolizumab pegol, a monthly subcutaneous treatment, on the HRQoL of patients with moderate-to-severe active Crohn's disease in a phase II placebo-controlled study [18]. HRQoL was assessed using the IBDQ.

\section{Materials and methods}

\section{Ethical conduct}

This study was approved by the Independent Ethics Committee/Institutional Review Board for each center before initiation. It was conducted in accordance with the International Conference for Harmonization Guidelines for Good Clinical Practice and the declaration of Helsinki (revised 1996).

Written informed consent was obtained from each patient at screening before any study procedures were performed. 


\section{Patients}

Adult patients (age $\geq 18$ years) with moderate-to-severe active Crohn's disease, as defined by a CDAI score of 220450 points during the week before the administration of the first dose of study drug, were eligible for the study. Exclusion criteria included suspected or diagnosed abscess, a bowel perforation or evidence of non-inflammatory obstruction in 6 months before screening, extensive bowel resection, a functional colostomy or ileostomy, or a known history of tuberculosis. Concomitant medication was allowed, provided that doses were stable and could be continued for the 12-week double-blind period and the 8-week follow-up.

\section{Study design}

This was a multicenter, randomized, double-blind, placebocontrolled, 12-week study conducted at 58 international centers between February 2001 and March 2002. An 8 -week follow-up period allowed collection of additional safety data. At screening, patients with moderateto-severe active Crohn's disease were stratified according to concomitant steroids, immunosuppressants, or long-term anti-infectives. Eligible patients were randomized $(1: 1: 1: 1)$ to receive certolizumab pegol $(100,200$, or $400 \mathrm{mg}$ ) or placebo $(0.9 \% w / v$ saline $)$ by subcutaneous injection at weeks 0, 4, and 8 (Fig. 1). Before dosing, patients' demography, medical history, and concomitant diseases were recorded.

\section{Outcomes}

The primary endpoint of the study was the proportion of patients achieving a clinical response $[\geq 100$-point decrease in CDAI score or CDAI score $\leq 150$ points (remission)] at week 12. HRQoL was a secondary endpoint evaluated at baseline (week 0, pre-injection) and at weeks 2, 4, 6, 8, 10, and 12 using the 32-item self-administered IBDQ. The IBDQ is a disease-specific HRQoL measure. The questionnaire assesses the four aspects of a patient's life that are affected by IBD: symptoms directly related to the primary bowel symptoms, systemic symptoms, emotional function, and social function [26]. The reliability, validity, and responsiveness of the IBDQ have been demonstrated by Guyatt et al. [26, 27] and Irvine et al. [7, 28]. The IBDQ is completed using a 7-point Likert response for each question. Total IBDQ scores range from 32 to 224, with a higher score indicating better HRQoL. Remission is generally indicated by a score of at least 170 points, and a change of 16 points is regarded as clinically meaningful [7]. In addition to a total score, domain scores can be calculated for the Bowel Symptoms, Systemic Symptoms, Emotional Function, and Social Function domains. IBDQ measurements were performed in parallel with determination of CDAI score and serum concentrations of $\mathrm{C}$-reactive protein (CRP). Official IBDQ versions translated into Danish, French, German, and Swedish were used. Our own translations were used for Russian, Serbian, and Afrikaans. To assess whether our own translated versions of the IBDQ provided a valid measure of HRQoL, we compared scores of the translated versions with those of the official translated versions and evaluated those scores in relation to the patient's CDAI scores. A sensitivity analysis was also carried out to check for influence of specific item scores on the resulting total scores. The results of these analyses demonstrated that our own translated versions of the IBDQ provided a valid measure of HRQoL, comparable to the official, translated versions.

\section{Statistical analysis}

A sample size of 260 patients was calculated to give approximately $83 \%$ power to detect a true difference
Fig. 1 Study design (showing the total numbers of patients recruited into each treatment group)

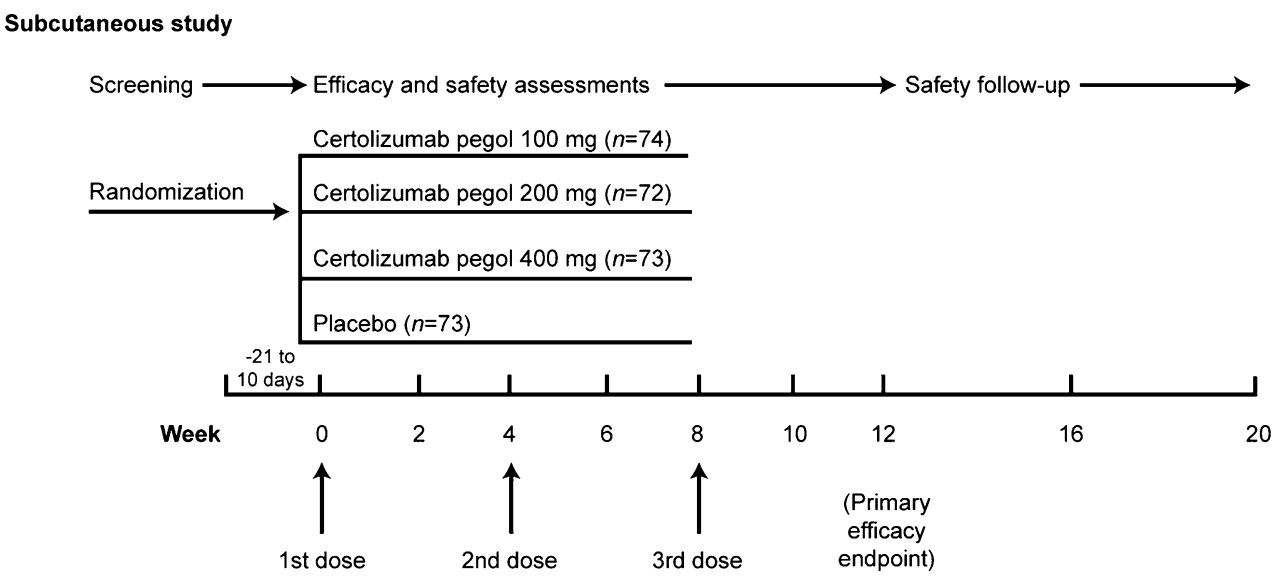


between treatment groups of $23 \%$ for the primary endpoint of the study, based on a placebo response rate of $12 \%$. After screening, patients were to be randomized in a 1:1:1:1 ratio (65 patients to each of the four treatment groups). Therefore, 195 patients were to receive certolizumab pegol and 65 were to receive placebo.

Efficacy was assessed for the intent-to-treat (ITT) population, which included all patients who received at least one injection and had at least one efficacy measurement after the first injection. Patients who terminated the trial prematurely were advanced to the end-of-study visit. The last observation carried forward method was used in cases where data were missing.

Post hoc analyses of IBDQ total score and individual domain scores were performed. These were purely exploratory in nature. Relationships between CDAI and IBDQ global scores at week 12 were assessed for the ITT population using Kendall's tau coefficient, a measure of the strength of dependence showing to what extent these two variables move in the same direction. Changes from baseline in IBDQ total score and individual domain scores for each treatment group were formally compared with the placebo group. Least-squares means, adjusted for stratum, pooled country, and baseline IBDQ score, were compared across treatment groups. Fisher's exact test was used to compare the proportion of patients who achieved remission (defined as an IBDQ total score of $\geq 170$ points) in each active treatment group with that for the placebo group at each week. The analyses were performed based on both the overall ITT population and in the subgroup of patients with elevated baseline CRP $(\geq 10 \mathrm{mg} / \mathrm{l}) . P$ values $\leq 0.05$ were considered to be statistically significant.

\section{Results}

The clinical efficacy and safety assessments of this phase II dose-finding study have been reported in detail elsewhere [21]. Because the $400 \mathrm{mg}$ dose was identified as being the most appropriate dose, this paper focuses on data for patients receiving certolizumab pegol $400 \mathrm{mg}$.

\section{Patients}

In total, 372 patients were screened of whom 292 patients were enrolled (CDAI score $<220$ points was the most common reason for screening failure). Of these 292 patients, 291 were included in the ITT population used to measure the efficacy endpoints according to CDAI scores [1 patient (400 mg group) was excluded because of missing efficacy data]. Baseline IBDQ scores were not obtained for one patient in the certolizumab pegol $100 \mathrm{mg}$ treatment group. The ITT analyses for the HRQoL evaluations therefore included data for 290 patients. Seventy-five patients $(25.7 \%)$ withdrew from the study by week 12 . The majority of withdrawals were a consequence of lack of improvement/disease progression.

Baseline CRP measurements were obtained for 290 of the 291 patients in the ITT population. Elevated baseline CRP levels $(\geq 10 \mathrm{mg} / \mathrm{l})$ were recorded for 119 patients $(41.0 \%)$. One of these patients was the patient in the certolizumab pegol $100 \mathrm{mg}$ treatment group who was excluded from analyses as a result of baseline IBDQ scores not being obtained. The subgroup analyses of IBDQ by baseline CRP status were therefore performed on data from 118 patients with an elevated baseline CRP concentration.

The four treatment groups were generally well matched in terms of demographic and clinical characteristics (including baseline IBDQ total score and concomitant medication profile; Table 1). In the ITT population, $21.6 \%$ of patients had received previous anti-TNF $\alpha$ therapy, and $15.5 \%$ had concomitant medication with both immunomodulators and steroids.

\section{Clinical response}

The onset of effect (clinical response) of certolizumab pegol was evident at week 2, when certolizumab pegol treatment produced a statistically significant improvement in CDAI score compared with placebo (certolizumab pegol $400 \mathrm{mg} 33.3 \%$ vs placebo $15.1 \% ; P=0.010$ ). Clinical response rates were highest in the certolizumab pegol $400 \mathrm{mg}$ group at all time points, with maximal response

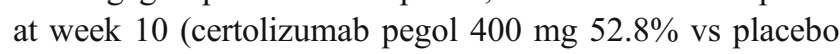
$30.1 \% ; P=0.006$ ) [21]. Lower CDAI score (representing lower disease severity) was associated with a higher IBDQ global score (representing better HRQoL), as reflected by a high negative Kendall's tau value $(-0.48 ; P<0.0001)$ Clinical response was observed irrespective of baseline CRP level.

\section{Improvement in HRQoL}

Patients demonstrated HRQoL improvements from baseline, as measured by change in IBDQ total score, by the first assessment point, week 2 [certolizumab pegol $100 \mathrm{mg}$, 16.6 points; certolizumab pegol $200 \mathrm{mg}, 21.8$ points $(P \leq$ 0.05 vs placebo); certolizumab pegol $400 \mathrm{mg}, 22.8$ points ( $P \leq 0.05$ vs placebo); placebo, 10.6 points] (Fig. 2). Patients receiving certolizumab pegol $400 \mathrm{mg}$ experienced statistically significantly greater improvements from baseline in IBDQ total score at all time points $(P \leq 0.05)$ compared with those receiving placebo. The greatest increase in IBDQ total score was recorded at week 10 (certolizumab pegol $400 \mathrm{mg} 32.2$ points vs 18.6 points for placebo; $P \leq 0.05$ ). Approximately half of the patients 
Table 1 Baseline demographic and clinical characteristics (intent to treat population used to measure efficacy endpoints according to Crohn's Disease Activity Index scores)

\begin{tabular}{|c|c|c|c|c|}
\hline & \multirow[t]{2}{*}{$\operatorname{Placebo}(n=73)$} & \multicolumn{3}{|l|}{ Certolizumab pegol } \\
\hline & & $100 \mathrm{mg}(n=74)$ & $200 \mathrm{mg}(n=72)$ & $400 \mathrm{mg}(n=72)$ \\
\hline Mean CDAI score (range) & $291.5(206-448)$ & $299.2(194-520)$ & $310.7(184-446)$ & $304.5(204-461)$ \\
\hline Mean IBDQ score (range) ${ }^{\mathrm{a}}$ & $122.9(61-190)$ & $132.2(66-189)^{b}$ & $122.9(74-189)$ & $126.5(71-177)$ \\
\hline Geometric mean plasma CRP, mg/l (range) & $7.268(0.27-86.10)$ & $6.231(0.15-141.00)^{\mathrm{b}}$ & $6.475(0.17-127.00)$ & $7.738(0.35-128.28)$ \\
\hline $\mathrm{CRP} \geq 10 \mathrm{mg} / 1, n(\%)$ & $28(38.4)$ & $31(42.5)^{\mathrm{b}}$ & $28(38.9)$ & $32(44.4)$ \\
\hline \multicolumn{5}{|l|}{ Concomitant medications, $n(\%)$} \\
\hline Aminosalicylates & $29(39.7)$ & $37(50.0)$ & $32(44.4)$ & $28(38.9)$ \\
\hline Anti-infectives & $7(9.6)$ & $6(8.1)$ & $7(9.7)$ & $6(8.3)$ \\
\hline Antidiarrheals & $10(13.7)$ & $19(25.7)$ & $16(22.2)$ & $12(16.7)$ \\
\hline Steroids & $29(39.7)$ & $24(32.4)$ & $29(40.3)$ & $22(30.6)$ \\
\hline Codeine and derivatives & $6(8.2)$ & $5(6.8)$ & $5(6.9)$ & $2(2.8)$ \\
\hline \multicolumn{5}{|l|}{ Immunomodulators } \\
\hline Azathioprine & $17(23.3)$ & $13(17.6)$ & $23(31.9)$ & $22(30.6)$ \\
\hline 6-Mercaptopurine & $4(5.5)$ & $9(12.2)$ & $2(2.8)$ & $2(2.8)$ \\
\hline Methotrexate & $5(6.8)$ & $4(5.4)$ & $4(5.6)$ & $3(4.2)$ \\
\hline
\end{tabular}

$C D A I$ Crohn's Disease Activity Index; $C R P$ C-reactive protein; IBDQ Inflammatory Bowel Disease Questionnaire; $n$ number of patients

${ }^{\text {a }}$ Maximum score is 224 points.

${ }^{\mathrm{b}}$ Data missing for one patient.

treated with certolizumab pegol $400 \mathrm{mg}$ demonstrated clinically meaningful improvements in IBDQ total score ( $\geq 16$-point increase) at week $2(52.8 \%)$ and at week 12 $(66.7 \%)$.

As early as week 2, patients receiving certolizumab pegol $400 \mathrm{mg}$ demonstrated statistically significant improvements in the Bowel Symptoms and Emotional Function domains of the IBDQ relative to placebo (Fig. 3). Improvement in the Systemic Symptoms domain score approached statistical significance at week $2(P=$ $0.054)$. These improvements were generally dose-related (Figs. 3a-d). Interestingly, patients in the certolizumab pegol $200 \mathrm{mg}$ group achieved statistically significantly greater improvements than those receiving placebo in IBDQ total score and all four IBDQ domains at week 2 (Figs. 2 and 3a-d).

Emotional Function and Systemic Symptoms were the domains that patients reported as being most improved by certolizumab pegol treatment. At every assessment, patients receiving certolizumab pegol $400 \mathrm{mg}$ showed statistically significantly $(P \leq 0.05)$ greater improvements in Emotional Function domain scores than those receiving placebo (Fig. 3c). They also demonstrated statistically significantly greater improvements in Systemic Symptoms domain scores than those receiving placebo at weeks $4,8,10$, and 12 (Fig. 3b). The improvements patients experienced in
Fig. 2 Mean change from baseline in Inflammatory Bowel Disease Questionnaire $(I B D Q)$ total score during 12 weeks' subcutaneous treatment with either certolizumab pegol or placebo in patients with moderate-to-severe Crohn's disease (intent-to-treat population); least-squares means (adjusted for stratum, pooled country, and baseline score)

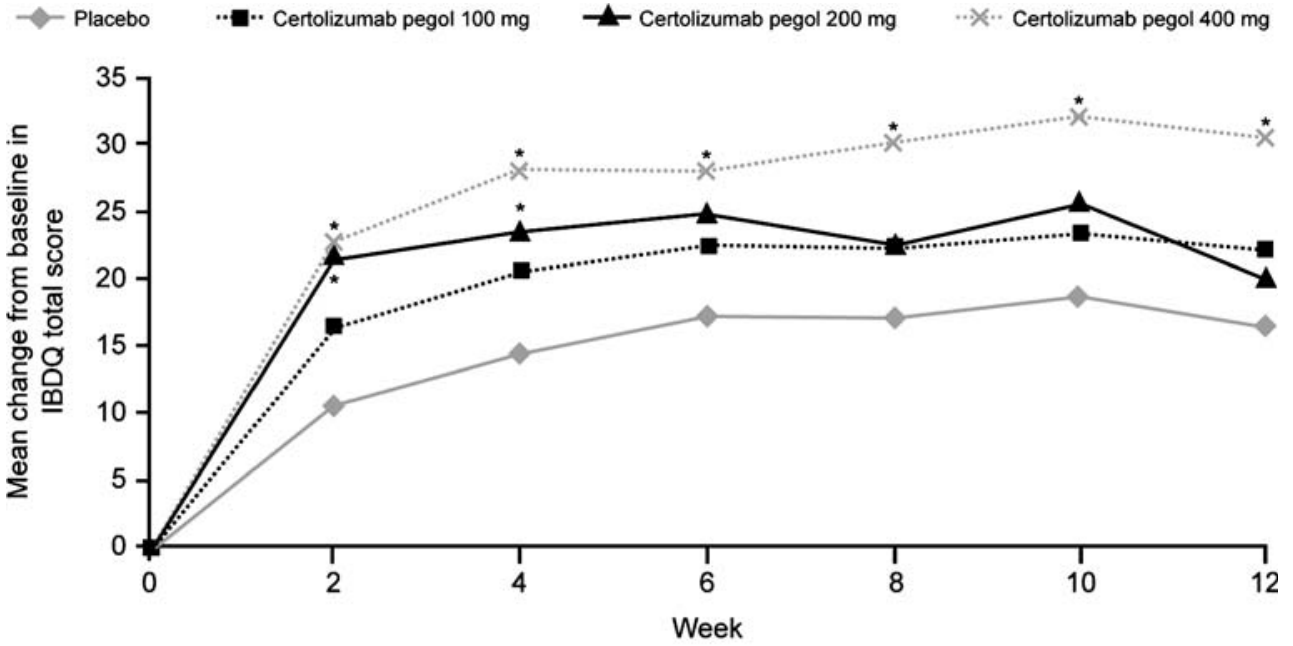

${ }^{\star} P \leq 0.05$ difference from placebo in least-squares means 

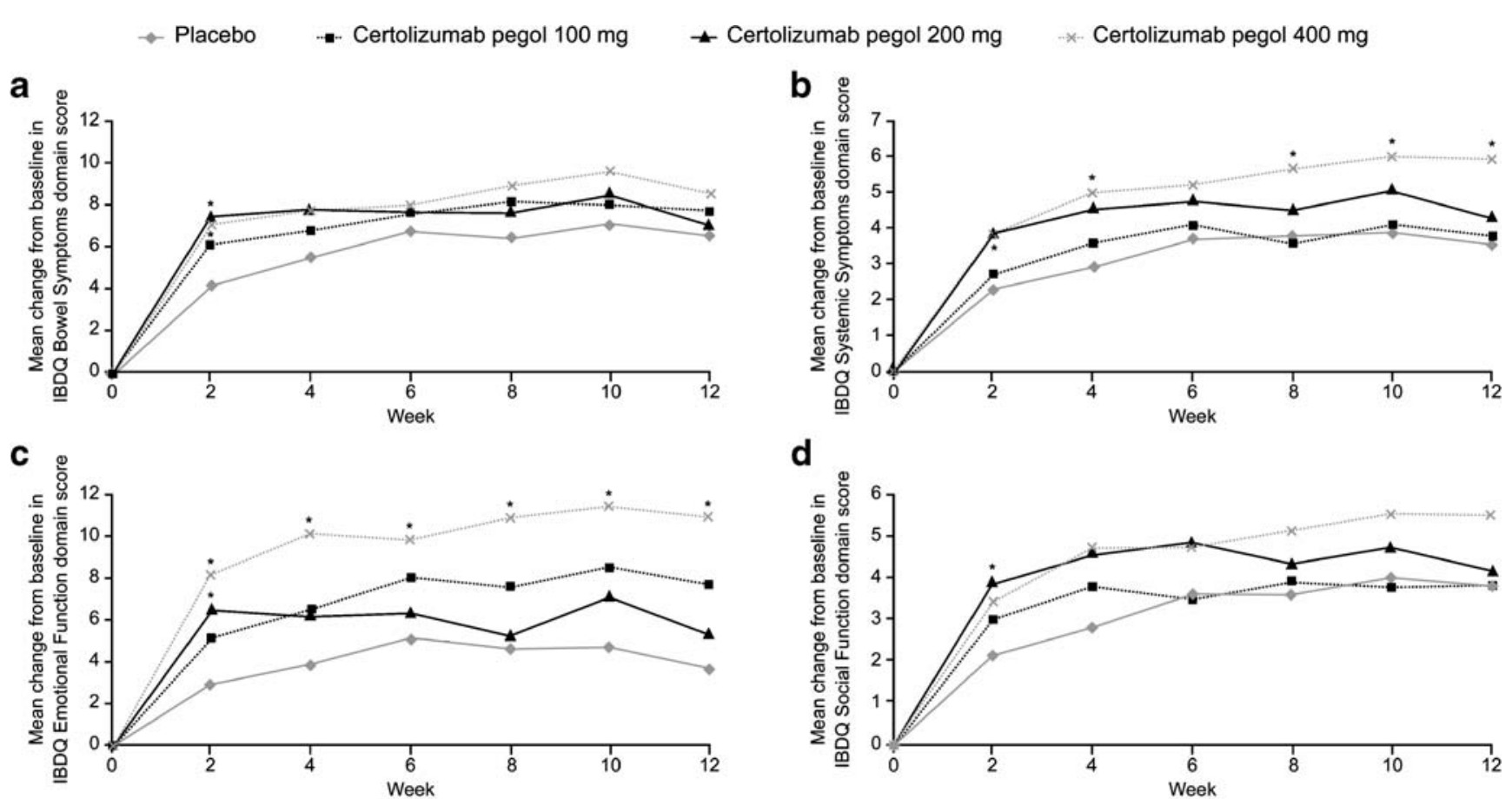

d

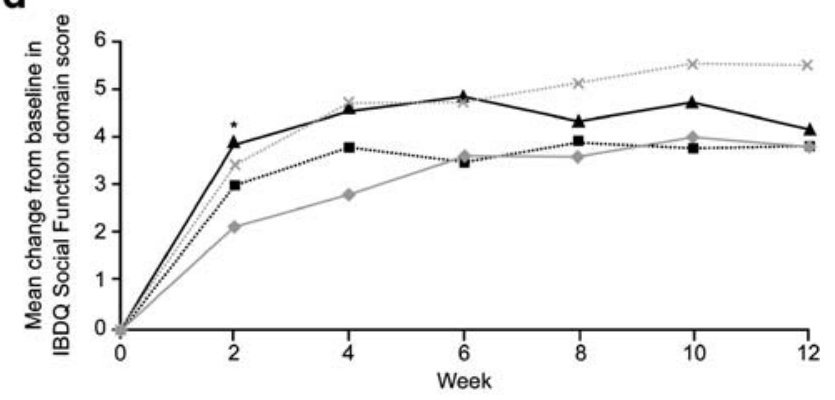

${ }^{\star} P \leq 0.05$ difference from placebo in least-squares means.

Fig. 3 Mean change from baseline in Inflammatory Bowel Disease Questionnaire (IBDQ) domain scores during 12 weeks subcutaneous treatment with either certolizumab pegol or placebo in patients with moderate-to-severe Crohn's disease (intent-to-treat

population); least-squares means (adjusted for stratum, pooled country, and baseline score): a Bowel Symptoms domain, b Systemic Symptoms domain, c Emotional Function domain, and d Social Function domain

Social Function domain scores approached statistical significance $(P=0.054)$ at week 4 (Fig. 3d).

The remission rate in the certolizumab pegol $400 \mathrm{mg}$ group was highest at week 10 . This was statistically significantly greater than in the placebo group (Table 2). The proportion of patients achieving remission in the certolizumab pegol $400 \mathrm{mg}$ group was also statistically significantly greater than in the placebo group at weeks 6 , 8 , and 12. The subgroup of patients with elevated CRP

showed similar improvements in IBDQ scores to those observed in the ITT population.

\section{Discussion}

Patients with Crohn's disease often have poor HRQoL [29], with disease-related concerns, such as worry about needing surgery, being the main causal factor [10]. It therefore

Table 2 Proportion of patients achieving remission defined by Inflammatory Bowel Disease Questionnaire total score ( $\geq 170$ points)

Patients (\%), intent-to-treat population $(n=290)$

\begin{tabular}{lllll}
\hline \multirow{2}{*}{ Week } & Placebo $(n=73)$ & \multicolumn{2}{l}{ Certolizumab pegol } \\
\cline { 3 - 4 } & & $100 \mathrm{mg}(n=73)$ & $200 \mathrm{mg}(n=72)$ & $400 \mathrm{mg}(n=72)$ \\
\hline 2 & 17.8 & 32.9 & 26.4 & 33.3 \\
4 & 19.2 & $37.0^{\mathrm{a} *}$ & 30.6 & $38.9^{*}$ \\
6 & 17.8 & $35.6^{*}$ & 29.2 & $38.9^{*}$ \\
8 & 21.9 & 35.6 & 36.1 & $47.2^{*}$ \\
10 & 27.4 & 43.8 & 23.6 & $38.9 *$ \\
12 & 23.3 & 38.4 & & 40.8 \\
\hline
\end{tabular}

${ }^{a}$ The higher remission rate at week 2 in the certolizumab pegol $100 \mathrm{mg}$ group compared with higher-dose groups may reflect the slightly higher mean Inflammatory Bowel Disease Questionnaire (IBDQ) score at baseline in this group. However, certolizumab pegol $400 \mathrm{mg}$ resulted in the greatest mean change in IBDQ at all time points.

${ }^{*} P \leq 0.05$ vs placebo 
follows that treatments relieving the symptoms of Crohn's disease and/or reducing the risk of surgery should improve HRQoL in patients with Crohn's disease.

Certolizumab pegol administered subcutaneously every 4 weeks is a rapid and clinically effective treatment of moderate-to-severe Crohn's disease with the $400 \mathrm{mg}$ dose (highest dose tested) inducing the highest response rates $[21,22,23]$. This analysis indicates that such clinical findings are accompanied by improvements in HRQoL.

Certolizumab pegol $400 \mathrm{mg}$ appears to exert a rapid, consistently positive effect on HRQoL in patients with moderate-to-severe Crohn's disease. Patients who received certolizumab pegol $400 \mathrm{mg}$ demonstrated statistically significantly greater improvements in IBDQ total score than those in the placebo group as early as week 2 and at all subsequent time points. As a reflection of the lower baseline IBDQ scores in the $400 \mathrm{mg}$ group, patients in this group experienced the greatest improvement, despite the remission rate (which is the proportion of patients reaching a predefined score) being higher in the $100 \mathrm{mg}$ group. Improvements in HRQoL were not dependent on baseline CRP level. Higher baseline CRP concentration was associated with greater improvement in clinical variables in this phase II study [21], but such a relationship has not been evident in phase III studies [30]. In addition, patients receiving certolizumab pegol $200 \mathrm{mg}$ showed a statistically significantly greater change from baseline in IBDQ total score than those receiving placebo at weeks 2 and 4. Collectively, these findings suggest that certolizumab pegol has an early treatment effect in patients with moderate-to-severe Crohn's disease. The benefits of certolizumab pegol on HRQoL were also apparent in the phase III studies [22, 23, 31, 32].

Improvements in emotional well-being (e.g. depression, anxiety, irritability, and anger resulting from bowel problems) and systemic symptom domains were particularly marked with certolizumab pegol treatment. It appears that the improvements in these two domains of the IBDQ are largely responsible for the reported beneficial effect of certolizumab pegol on HRQoL. Overall, these findings suggest that certolizumab pegol alleviates the psychological symptoms associated with Crohn's disease and improves a patient's general well-being, in addition to providing clinical benefits in terms of CDAI response.

HRQoL provides an integral picture of the interactions between a patient's disease, their treatment, and quality of life-positive effects resulting from the efficacy of a treatment and negative effects caused by adverse events are evaluated. Few trials have examined the effects of conventional agents upon HRQoL in patients with Crohn's disease. While corticosteroids are effective in controlling acute Crohn's disease and are reported to improve IBDQ scores [33], the potentially serious adverse events associated with corticosteroids may negate any positive effects on HRQoL gained through control of symptoms. Additionally, corticosteroids are not suitable for maintenance treatment. Improvements in HRQoL have been observed with methotrexate treatment in a large, randomized, doubleblind, placebo-controlled study [34]. However, 17\% of patients (16/94) receiving methotrexate were withdrawn from the study because of adverse events compared with $2 \%$ of placebo-treated patients $(1 / 47)$.

The improvements in HRQoL observed with certolizumab pegol in this study appear to be similar to those reported in patients with Crohn's disease after treatment with infliximab [8, 17, 35]. Similarly, natalizumab has been shown to improve HRQoL in patients with Crohn's disease [36].

Given the detrimental effects of Crohn's disease on physical and psychosocial functioning, additional research is needed to assess the impact of currently available and newer therapies on HRQoL. Although HRQoL was evaluated using the self-administered IBDQ, which has proved to be a valid and reliable disease-specific instrument for determining health status in patients with Crohn's disease [7], the analyses presented in this paper were purely exploratory in nature, and firm conclusions cannot be drawn from the results described. However, clinical benefit was also accompanied by improved HRQoL in the phase III studies [22, 23, 31, 32]. Further benefits may be gained through the good tolerability of certolizumab pegol [37] and convenience of subcutaneous dosing with certolizumab pegol once every 4 weeks.

\section{Conclusions}

This study demonstrates that the clinical efficacy of certolizumab pegol in patients with moderate-to-severe Crohn's disease, which is evident within 2 weeks of injection, is paralleled by improvements in HRQoL. The benefits of certolizumab pegol were most pronounced at the highest dose tested (400 g). Improvements in emotional well-being and systemic symptoms appear to be largely responsible for the observed beneficial effect of certolizumab pegol on HRQoL.

Acknowledgements This study was supported by a research grant from UCB, Slough, UK.

Conflicts of interest statement Stefan Schreiber, Richard Fedorak, and Brian Feagan have served as consultants for UCB. Dorothy Keininger and Liz O'Neil are employees of UCB. Paul Rutgeerts has served as consultant for UCB and received speaker fees and research support.

\section{References}

1. Gazzard BG (1987) The quality of life in Crohn's disease. Gut $28: 378-381$ 
2. Cohen RD (2002) The quality of life in patients with Crohn's disease. Aliment Pharmacol Ther 16:1603-1609

3. Walker SR, Rosser RM (eds) (1987) Quality of life: assessment and application. CMR Workshop. MTP Press, Lancaster, UK

4. Garrett JW, Drossman DA (1990) Health status in IBD: biological and behavioral considerations. Gastroenterology 99:90-96

5. Drossman DA, Leserman J, Li ZM, Mitchell CM, Zagami EA, Patrick DL (1991) The rating form of IBD patient concern: a new measure of health status. Psychosom Med 53:701-712

6. Best WR, Becktel JM, Singleton JW, Kern FJn (1976) Development of a Crohn's disease activity index. National Cooperative Crohn's Disease Study. Gastroenterology 70:439-444

7. Irvine EJ, Feagan B, Rochon J, Archambault A, Fedorak RN, Groll A, Kinnear D, Saibil F, McDonald JW (1994) Quality of life: a valid and reliable measure of therapeutic efficacy in the treatment of inflammatory bowel disease. Canadian Crohn's Relapse Prevention Trial Study Group. Gastroenterology 106:287-296

8. Feagan BG, Yan S, Bala M, Bao W, Lichtenstein GR (2003) The effects of infliximab maintenance therapy on health-related quality of life. Am J Gastroenterol 98:2232-2238

9. Blondel-Kucharski F, Chircop C, Marquis P, Cortot A, Baron F, Gendre JP, Colombel JF, Groupe d'Etudes Therapeutique des Affections Inflammatoires Digestives (GETAID) (2001) Healthrelated quality of life in Crohn's disease; a prospective longitudinal study in 231 patients. Am J Gastroenterol 96:2915-2920

10. Canavan C, Abrams KR, Hawthorne B, Drossman D, Mayberry JF (2006) Long-term prognosis in Crohn's disease: factors that affect quality of life. Aliment Pharmacol Ther 23:377-385

11. Sandborn WJ (2000) Steroid-dependent Crohn's disease. Can J Gastroenterol 14(Suppl. C):17C-22C

12. Rutgeerts PJ (2001) Review article: the limitations of corticosteroid therapy in Crohn's disease. Aliment Pharmacol Ther 15:1515-1525

13. Bernklev T, Jahnsen J, Schulz T, Sauar J, Lygren I, Henriksen M, Stray N, Kjellevold O, Aadland E, Vatn M, Moum B (2005) Course of disease, drug treatment and health-related quality of life in patients with inflammatory bowel disease 5 years after initial diagnosis. Eur J Gastrenterol Hepatol 17:1037-1045

14. Drossman DA, Patrick DL, Mitchell CM, Zagami EA, Appelbaum MI (1989) Health-related quality of life in inflammatory bowel disease: Functional status and patient worries and concerns. Dig Dis Sci 34:1379-1386

15. van Deventer SJ (1997) Tumour necrosis factor and Crohn's disease. Gut 40:443-448

16. Hanauer SB, Feagan BG, Lichtenstein GR, Mayer LF, Schreiber S, Colombel JF, Rachmilewitz D, Wolf DC, Olson A, Bao W, Rutgeerts P, ACCENT I Study Group (2002) Maintenance infliximab for Crohn's disease: the ACCENT I randomized trial. ACCENT I Study Group. Lancet 359:1541-1549

17. Lichtenstein GR, Bala M, Han C, DeWoody K, Schaible T (2002) Infliximab improves quality of life in patients with Crohn's disease. Inflamm Bowel Dis 8:237-243

18. Baert F, Noman M, Vermeire S, Van Assche G, D'Haens G, Carbonez A, Rutgeerts P (2003) Influence of immunogenicity on the long-term efficacy of infliximab in Crohn's disease. N Engl J Med 348:601-608

19. Rutgeerts P (2002) A critical assessment of new therapies in inflammatory bowel disease. J Gastroenterol Hepatol 17:S176-S185

20. Fossati G, Nesbitt A (2005) In vitro complement-dependent cytotoxicity and antibody-dependent cellular cytotoxicity by the antiTNF agents adalimumab, etanercept, infliximab, and certolizumab pegol. Poster presentation at American College of Gastroenterology Annual Scientific Meeting and Postgraduate Course, Hawaii, October 28-November 2, 2005 (Abstract 807)
21. Schreiber S, Rutgeerts P, Fedorak RN, Khaliq-Kareemi M, Kamm MA, Boivin M, Bernstein CN, Staun M, Thomsen OO, Innes A, CDP870 Crohn's Disease Study Group (2005) A randomized, placebo-controlled trial of certolizumab pegol (CDP870) for treatment of Crohn's disease. The CDP870 Crohn's Disease Study Group. Gastroenterology 129:807-818

22. Sandborn WJ, Feagan BG, Stoinov S et al (2007) Certolizumab pegol for the treatment of Crohn's disease. N Engl J Med 357:228-238

23. Schreiber S, Khaliq-Kareemi M, Lawrance IC et al (2007) Certolizumab pegol maintenance therapy for Crohn's disease. N Engl J Med 357:239-250

24. Keystone E, Choy EH, Kalden J, Klareskog L, Sany J, Smolen J (2001) CDP870, a novel, PEGylated, humanized TNF-alpha inhibitor, is effective in treating the signs and symptoms of rheumatoid arthritis (RA). Arthritis Rheum 44:2946

25. Choy EH, Hazleman B, Smith M, Moss K, Lisi L, Scott DG, Patel J, Sopwith M, Isenberg DA (2002) Efficacy of a novel humanized anti-TNF fragment (CDP870) in patients with rheumatoid arthritis: a phase II double-blinded, randomized, dose-escalating trial. Rheumatology 42:1133-1137

26. Guyatt GH, Mitchell A, Irvine EJ, Singer J, Williams N, Goodacre R, Tompkins C (1989) A new measure of health status for clinical trials in inflammatory bowel disease. Gastroenterology 96:804-810

27. Guyatt GH, Deyo RA, Carlson M, Levine MN, Mitchell A (1989) Responsiveness and validity in health status management: a clarification. J Clin Epidemiol 42:403-408

28. Irvine EJ (1999) Development and subsequent refinement of the inflammatory bowel disease questionnaire: a quality of life instrument for adults with inflammatory bowel disease. J Pediatr Gastroenterol Nutr 28:S23-S27

29. Casellas F, Lopez-Vivancos J, Badia X, Vilaseca J, Malagelada JR (2001) Influence of inflammatory bowel disease on different dimensions of quality of life. Eur J Gastroenterol Hepatol 13:567-572

30. Schreiber S, Hanauer SB, Lichtenstein GR, Sandborn WJ (2007) Superior efficacy of certolizumab pegol in early Crohn's disease is independent of CRP status. Gastroenterology 132(4 Suppl 1): A510-A511 (Abstract T1298)

31. Feagan B, Coteur G, Keininger DL, Schreiber S (2006) Sustained improvement in health-related quality of life following certolizumab pegol $400 \mathrm{mg}$ every 4 weeks in patients with Crohn's disease: data from PRECiSE 2. Gut 55(Suppl 5):A124(Abstract MON-G-219)

32. Schreiber S, Sandborn W, Rutgeerts P, Coteur G, Keininger DL, Feagan B (2007) Induction of health-related quality-of-life response and remission in Crohn's disease patients following subcutaneous treatment with certolizumab pegol $400 \mathrm{mg}$ : data from PRECiSE 1. Gastroenterology 132(4 Suppl 1):A508(Abstract T1287)

33. Greenberg GR, Feagan BG, Martin F, Sutherland LR, Thomson AB, Williams CN, Nilsson LG, Persson T (1994) Oral budesonide for active Crohn's disease. N Engl J Med 331:836-841

34. Feagan BG, Rochon J, Fedorak RN et al (1995) Methotrexate for the treatment of Crohn's disease. The North American Crohn's Study Group Investigators. N Engl J Med 332:292-297

35. van Balkom Schoon EJ, Stockbrügger RW et al (2002) Effects of anti-tumour necrosis factor-alpha therapy on the quality of life in Crohn's disease. Ailment Pharmacol Ther 16:1101-1107

36. Ghosh S, Goldin E, Gordon FH, for the Natalizumab PanEuropean Study Group et al (2003) N Engl J Med 348:24-32

37. Schreiber S, Feagan B, Hanauer SB, Rutgeerts P, McColm JA, Sandborn WJ (2006) Safety and tolerability of subcutaneous certolizumab pegol in active Crohn's disease: results from two Phase III studies (PRECiSE program). Gastroenterology 130 (Suppl 2):A1-A912 